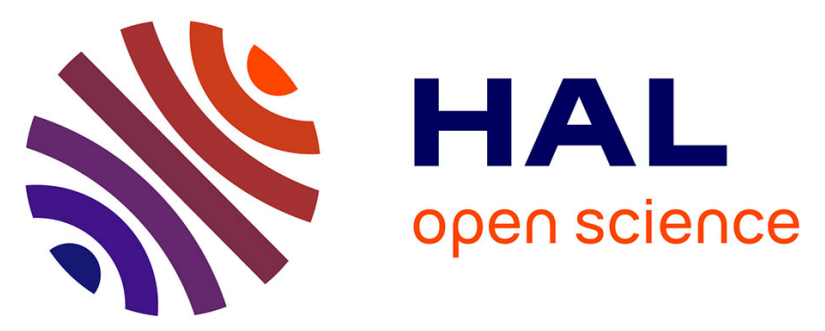

\title{
Is self-assessment by patients of disease activity acceptable over the long term in rheumatoid arthritis? A 3-year follow-up of 771 patients
}

Laure Gossec, Françoise Fayet, Martin Soubrier, Frantz Foissac, Anna Moltó, Pascal Richette, Catherine Beauvais, Adeline Ruyssen-Witrand, Aleth Perdriger, Isabelle Chary-Valckenaere, et al.

\section{To cite this version:}

Laure Gossec, Françoise Fayet, Martin Soubrier, Frantz Foissac, Anna Moltó, et al.. Is self-assessment by patients of disease activity acceptable over the long term in rheumatoid arthritis? A 3-year followup of 771 patients. Rheumatology, In press, 58 (8), pp.1498-1499. 10.1093/rheumatology/kez094 . hal-02167073

\section{HAL Id: hal-02167073 \\ https://hal-univ-rennes1.archives-ouvertes.fr/hal-02167073}

Submitted on 5 Jul 2019

HAL is a multi-disciplinary open access archive for the deposit and dissemination of scientific research documents, whether they are published or not. The documents may come from teaching and research institutions in France or abroad, or from public or private research centers.
L'archive ouverte pluridisciplinaire HAL, est destinée au dépôt et à la diffusion de documents scientifiques de niveau recherche, publiés ou non, émanant des établissements d'enseignement et de recherche français ou étrangers, des laboratoires publics ou privés. 


\title{
Is self-assessment by patients of disease activity acceptable over the long term in rheumatoid arthritis? A 3-year follow-up of 771 patients
}

Laure Gossec $^{1,2}$, Françoise Fayet ${ }^{3}$, Martin Soubrier ${ }^{3}$, Frantz Foissac ${ }^{4,5}$, Anna Molto ${ }^{6,7}$, Pascal Richette $^{8}$, Catherine Beauvais ${ }^{9}$, Adeline Ruyssen-Witrand ${ }^{10}$, Aleth Perdriger ${ }^{11}$, Isabelle Chary-Valckenaere ${ }^{12}$, Gaël Mouterde ${ }^{13}$, Emmanuelle Dernis ${ }^{14}$, Liana Euller-Ziegler ${ }^{15}$, RenéMarc Flipo ${ }^{16}$, Mélanie Gilson ${ }^{17}$, Nathalie Balandraud ${ }^{18}$, Xavier Mariette ${ }^{19}$, Sophie Pouplin ${ }^{20}$, Thierry Marhadour ${ }^{21}$, Thierry Schaeverbeke ${ }^{22}$, Christelle Sordet ${ }^{23}$ Maxime Dougados $^{6,7}$

\begin{abstract}
'Sorbonne Université, Institut Pierre Louis d'Epidémiologie et de Santé Publique (iPLESP), INSERM UMR S 1136, Paris France. ${ }^{2}$ Rheumatology department, Pitié Salpêtrière hospital, APHP, Paris, France. ${ }^{3}$ Department of Rheumatology, CHU Clermont-Ferrand, Clermont-Ferrand, France. ${ }^{4}$ Clinical Research Unit Necker-Cochin, Assistance Publique-Hôpitaux de Paris, Paris, France. , ${ }^{5}$ EA7323,University Paris Descartes, Sorbonne Paris Cité, Paris, France, ${ }^{6}$ Rheumatology Department, Cochin Hospital, AP-HP, Paris, France. ${ }^{7}$ INSERM (U1153), Clinical Epidemiology and Biostatistics, PRES Sorbonne Paris-Cité, Paris Descartes University, Paris, France. ${ }^{8}$ UFR médicale, Université Paris Diderot, Paris, France; Fédération de Rhumatologie, APHP Hôpital Lariboisiére, Paris, France. 9Sorbonne Université, INSERM UMRS938, Paris France; Rheumatology department, St-Antoine Hospital, AP-HP, DHU i2B, Paris, France. ${ }^{10}$ UMR 1027 Inserm, Paul Sabatier University, Toulouse, France. ${ }^{11}$ Department of Rheumatology, South Hospital, Medecine Faculty, Rennes 1 University, Rennes, France. ${ }^{12}$ Department of Rheumatology, Nancy University Hospital, VandoeuvreLes-Nancy, France. ${ }^{13}$ Rheumatology department, Montpellier Hospital, Univ Montpellier, Montpellier, France. ${ }^{14}$ Department of Rheumatology, Le Mans Hospital, Le Mans, France. ${ }^{15}$ Department of Rheumatology, Hôpital Pasteur 2, Nice, France. ${ }^{16}$ Department of Rheumatology, CHU Roger Salengro Hospital, University of Lille 2, Lille, France. ${ }^{17}$ Department of Rheumatology, Grenoble-Alpes University Hospital, Echirolles, France. ${ }^{18}$ Department of Rheumatology, Marseille University Hospital, Marseille, France. ${ }^{19}$ Department of Rheumatology, AP-HP, Hôpitaux Universitaires Paris-Sud, Université ParisSud, INSERM UMR1184, Le Kremlin-Bicetre, France. 20Department of Rheumatology, Rouen Hospital, Rouen, France. ${ }^{21}$ Department of Rheumatology, CHU de la Cavale Blanche, Boulevard Tanguy Prigent, Brest, France ; INSERM 1227, Université Bretagne Occidentale, Brest, France. ${ }^{22}$ Department of Rheumatology, Pellegrin Hospital, Bordeaux University, CNRS 5164, Bordeaux, France. ${ }^{23}$ Department of Rheumatology, Hautepierre Hospital, Hopitaux Universitaire de Strasbourg, Fédération de médecine translationnelle, UMR INSERM 1109, Strasbourg, France
\end{abstract}

\section{Corresponding author}

Laure GOSSEC, Hôpital Pitié- Salpêtrière, Service de Rhumatologie, 47-83 bd de l'hôpital, 75013 PARIS France. Email : laure.gossec@gmail.com

Disclosures: No relevant disclosures for this study.

Funding: This work was supported by a grant from the French Ministry of Health (PHRC AOM 12072) and sponsored by Assistance Publique-Hôpitaux de Paris.

Key message: Self-assessment of disease activity is feasible in rheumatoid arthritis, but its frequency decreases over time. 
In rheumatoid arthritis (RA), regular assessment of disease activity is an integral part of a treat-to-target approach.[1] However, repeated, close-in-time consultations with the rheumatologist are not always feasible. In the Comorbidities and Education in Rheumatoid Arthritis (COMEDRA) trial, RA patients were trained to perform a self-assessment of Disease Activity Score on 28 joints (DAS28), termed auto-DAS (they were randomised to have this visit either at baseline, or after 6 months).[2] At the 6-month timepoint, the COMEDRA trial showed the feasibility of auto-DAS, and we found more therapeutic changes had been made in the auto-DAS arm.[2] The present letter reports the results of the open-label follow-up of this trial, after 3 years. The objective was to assess the feasibility over the long-term of autoDAS assessment, and determine the characteristics of patients adherent to auto-DAS.

This was an open long-term (2-4 years) extension of the 6 month randomized controlled COMEDRA trial of patients with definite, stable RA. Ethical approval (ethical committee CPP Ile de France VI, number 8-14) and informed patient consent were obtained. During a nurse visit, the importance of regular disease activity assessment was explained, as well as the principle of the DAS28. Patients were trained by a nurse to perform auto-DAS, using a video and teaching of self-assessment of joints (the training took approximately 30 minutes). It was suggested to them to perform this self-assessment regularly and to note it in a booklet. In the present follow-up, 2-4 years after the end of the trial, patients were seen in a face-to-face interview with a nurse and the frequency of auto-DAS was assessed through the auto-DAS booklet ( $\mathrm{N}=247$ ) and if unavailable, from patient questioning. Adherence to auto-DAS was defined as the performance of at least one auto-DAS more than 6 months after the end of the trial. Characteristics of adherent versus non adherent patients were compared by univariate and multivariate logistic regression analyses and included demographic and disease activity variables as well as the centre, according to its recruitment in the trial (centres were binarised as higher or lower than median inclusion number).

Of the 970 recruited patients, $771(79.5 \%)$ were followed up 3 years and had available data regarding auto-DAS: mean ( \pm standard deviation) age $61( \pm 11)$ years, median [interquartile range, IQR] disease duration 15 [9 - 23] years; 615 (80\%) were women and 534 (69\%) were currently taking a biologic. There were no notable differences between those followedup or not (data not shown). The mean baseline and 3-year DAS28 scores (calculated by the health professionals) were respectively $3.1 \pm 1.3$ and $2.8 \pm 1.4$, the mean $\mathrm{mHAQ}$ was 0.38 $( \pm 0.45)$. The inter-rater reliability (measured by intraclass correlation coefficient) of DAS28 between health professional and patient was 0.50 [95\% confidence interval $0.43-0.56$ ] at baseline and it was 0.62 [0.57-0.67] at 3 years. After 3 years, $354(46 \%)$ patients were adherent to auto-DAS. For adherent patients the median [IQR] number of auto-DAS performed was 5.4 [1.7 - 12.8] overall, i.e. 2.3 [0.8 - 5.9] per year. However among the adherent population, the number of patients who performed an auto-DAS at least once per year decreased over time (Figure) $(p<0.0001)$. In the multivariate analysis, only larger inclusion centres were significantly associated to an adherent behaviour (odds ratio 2.9 [95\% confidence interval $2.0-4.1], p<0.0001$ ).

These results confirmed the feasibility of auto-DAS. Auto-DAS may reflect flares and allow the health professional to obtain an overview of health status between visits.[3-5] These results further indicate that after a short training, many of these long-standing, moderately active RA patients continued to perform an auto-DAS, though the performance of auto-DAS decreased over time. It is of course possible that patients who self-reported autoDAS were not accurate. It is noteworthy that in this cohort, most patients did not receive any ongoing positive feedback on their auto-DAS. In the larger inclusions centres, auto-DAS adherence was higher. We hypothesise that a high number of patient inclusion reflected local strong involvement of physicians and nurses in the project. The results are suggesting a less optimal performance of the auto-DAS in the absence of discussion of the results of the autoDAS with the treating rheumatologist. It is noteworthy that patients in the present study had stable RA, usually in moderate disease activity. It is possible that auto-DAS is felt as worthwhile, when patients are flaring or otherwise doing poorly. Reversely, repeated 
assessments may pall for patients in long-term stable disease.[6] The decrease over time of auto-DAS, and previous studies of between-visit assessments (such as e-health tools can provide) indicate a benefit from feedback from the health care providers, to keep patient motivation up.[6,7]. These data emphasize the importance of a clear communication between the rheumatology team and the treating rheumatologist in order to explain clearly the objectives and the potential benefit of this initiative. These results thus suggest the necessity of a regular reinforcement of this initiative; which might be optimally performed by the rheumatology team during the recommended annual systematic and comprehensive review supervised by the rheumatology team. [8]

We conclude that self-assessment of disease activity is feasible in RA but positive reinforcement appears necessary. Further studies should analyse if outcomes are better for patients who perform self-assessments regularly.

\section{References}

1. Smolen JS, Breedveld FC, Burmester GR, Bykerk V, Dougados M, Emery P, et al. Treating rheumatoid arthritis to target: 2014 update of the recommendations of an international task force. Ann Rheum Dis. 2016;75:3-15.

2. Dougados $M$, Soubrier M, Perrodeau E, Gossec L, Fayet F, Gilson M, et al. Impact of a nurse-led programme on comorbidity management and impact of a patient selfassessment of disease activity on the management of rheumatoid arthritis: results of a prospective, multicentre, randomised, controlled trial (COMEDRA).Ann Rheum Dis. 2015 Sep;74:1725-33.

3. Markusse IM, Dirven L, Gerards AH, van Groenendael JH, Ronday HK, Kerstens PJ, et al. Disease flares in rheumatoid arthritis are associated with joint damage progression and disability: 10-year results from the BeSt study. Arthritis Res Ther. 2015;17:232.

4. Ometto F, Raffeiner B, Bernardi L, Bostsios C, Veronese N,4, Punzi L, et al. Selfreported flares are predictors of radiographic progression in rheumatoid arthritis patients in 28-joint disease activity score remission: a 24-month observational study. Arthritis Res Ther. 2016;18:89.

5. Portier A, Gossec L, Tubach F, Alfaiate T, Pham T, Saraux A, et al. Patient-perceived flares in rheumatoid arthritis: A sub-analysis of the STRASS treatment tapering strategy trial. Joint Bone Spine. 2017;84(5):577-581.

6. Gossec L, Cantagrel A, Soubrier M, Berthelot JM, Joubert JM, Combe B, et al. An ehealth interactive self-assessment website (Sanoia $\left.{ }^{8}\right)$ in rheumatoid arthritis. A 12month randomized controlled trial in 320 patients. Joint Bone Spine. 2018;85(6):709714.

7. Jacquemin C, Molto A, Servy H, Sellam J, Foltz V, Gandjbakhch F, et al. Flares assessed weekly in patients with rheumatoid arthritis or axial spondyloarthritis and relationship with physical activity measured using a connected activity tracker: a 3month study. RMD Open. 2017;3(1):e000434.

8. NICE quality standards for Rheumatoid arthritis in over 16s. https://www.nice.org.uk/guidance/qs33 accessed Dec 18, 2018. 
Figure title. Percentage of patients performing at least one auto-DAS per year, over time

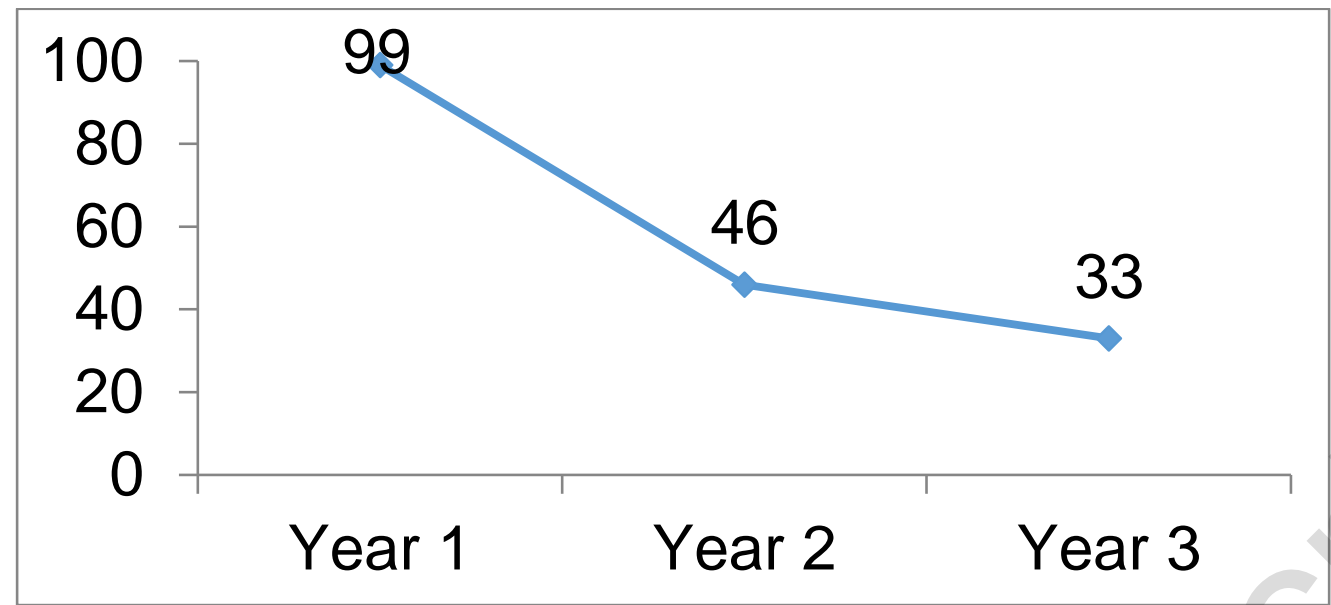

\section{Legend}

$X$ axis year of follow-up after the trial

$Y$ axis percentage of patients performing at least one auto-DAS each year, among patients considered adherent (i.e., having performed at least one auto-DAS more than 6 months after the end of the trial). 